Japan. J. Med. Sci. Bio1., 38, 155-168, 1985.

\title{
A LIGHT AND ELECTRON MICROSCOPIC EXAMINATION OF EHRLICHIA SENNETSU IN CULTURED HUMAN ENDOTHELIAL CELLS
}

Daryl J. KELLY, Melinda LEE and George E. LEWIS, Jr.

U.S. Arrmy Medical Research Unit, Institute for Medical Research, Kuala Lumpur 02-24, Malaysia

(Received Ju1y 8, 1985. Accepted October 16, 1985)

SUMMARY: Umbilical cord-derived human endothelial cells were used for the propagation of Ehrlichia sennetsu. Scanning electron microscopic studies revealed numerous pleomorphic ehrlichiae extending from the surface of infected human endothelial cells. Transmission electron microscopic examination of the cells revealed $E$. sennetsu-induced cytopathic changes at the ultrastructural level. Ehrlichiae of variable size, shape and density were located individually and in clusters enclosed within membrane lined vacuoles. The cultured human endothelial cell provides an optimal environment for the growth of $E$. sennetsu and is a suitable in vitro model for the study of the cytopathic effects of this human pathogen.

\section{INTRODUCTION}

Ehriichia (Rickettsia) sennetsu is the etiologic agent of a well-defined human disease syndrome known as sennetsu or glandular fever (1). This disease has been described as a cause of febrile illness in western Japan although recent reports suggest a much wider area of distribution $(2,3)$. Signs and symptoms of the disease include fever, sore throat, lymphadenopathy, and lymphocytosis; sennetsu fever has been described as being clinically indistinguishable from infectious mononucleosis (1). Recent antibody cross-reactivity studies strongly suggest that $E$. sennetsu shares certain antigenic moleties with $E$. canis (4), the causative agent of canine ehrlichiosis (tropical canine pancytopenia), a tick-transmitted infectious disease of dogs, and thus has formed a basis for the recent reclassification of the sennetsu agent from Rickettsia to Ehrilichia spp. (2), a genus heretofor containing only nonhuman pathogens.

This research was supported by Research Grant No.DAMD17-83-G-9502 from the U.S. Army Medical Research and Development Command, Fort Detrick, Frederick, MD 21701-5012, U.S.A.

In conducting the research described in this report, the investigators adhered to the 'Guide for the Care and Use of Laboratory Animals', prepared by the Committee on Care and Use of Laboratory Animals of the Institute of Laboratory Animal Resources, National Research Council (DHEW Publication No.(NIH) 80-23, Revised 1978 - reprinted 1980).

Address reprint requests to: Commander, U.S. Army Medical Research Unit, Institute for Medical Research, Jalan Pahang, Kuala Lumpur 02-14, Malaysia. 
Since the first isolation of $E$. sennetsu (1), the agent has been propagated in vitro in many established continuous cell lines including HeLa cells (5), African green monkey kidney cells (BS-C-1) (6), murine fibroblast (L-929) (7), and human amnion derived FL cells (8). In addition, this human pathogen has been propagated in primary culture in both canine (3) and human blood monocytes (4) but has not been studied in cultured human endothelial (HE) cells.

A major characteristic of both rickettsial $(9,10)$ and ehrlichial diseases (11) is the involvement of the endothelial cells of small veins, arteries, and capillaries. The importance of the endothelial cell as a target cell in the pathogenesis of rickettsial diseases has been emphasized in recent studies $(12,13)$. It follows that the endothelial cell may be an important site of involvement in the disease process of sennetsu rickettsiosis $(14,15)$.

In this report we use light and electron microscopy to characterize $E$. sennetsu in, and describe the induced host-cell changes of, human umbilical cord-derived endothelial cells experimentally infected with this organism.

\section{MATERIALS AND METHODS}

Mice: Outbred ICR mice (Division of Laboratory Animal Resources, Institute for Medical Research, Kuala Lumpur, Malaysia) aged 4-8 weeks and of either sex were used throughout the study.

Ehrlichiae: The Miyayama prototype strain E. (Rickettsia) sennetsu (mouse passage 397) originally isolated by Misao and Kobayashi (1) (kindly provied by Dr. N. Tachibana, Miyazaki Medical School, Miyazaki, Japan) was used in this study. Spleens of mice infected with the ehrlichial suspension were aseptically harvested, blended with Snyder I diluent (16) to yield a $20 \%(\mathrm{w} / \mathrm{v})$ suspension by a modification of the method of Shirai et al (17). Aliquots were titered according to the method of Jackson and Smadel (18). The $50 \%$ mouse lethal dose (MLD 50 ) was calculated by the Spearman Karber method (19).

Isolation and culture of human endothelial cells: Human umbilical cord-derived vascular endothelial cells were prepared by a modification of the method of Gimbrone (20) and Jaffe (21). Isolated $\mathrm{HE}$ cells were seeded into $75 \mathrm{~cm}^{2}$ plastic flasks (Costar, Cambridge, MA, USA) and propagated in Medium 199 (Earle's Balanced Salts Solution(EBSS), Gibco, Grand Island, NY, USA) containing $20 \%$ heat-inactivated fetal bovine serum. Cells were incubated at $35 \mathrm{C}$ in an atmosphere of $5 \% \mathrm{CO}_{2}$ in air and passaged by use of $0.25 \%$ trypsin (Type II, Sigma, St. Louis, MO, USA) $-0.02 \%$ EDTA. Early passaged cells not exceeding passage 7 were used in this study. Cells isolated from the umbilical cord vein were identified as endothelial cells by the criteria of Jaffe et al. (21) including the presence of human antihemophilic factor (AHF, factor VIII) $(22,23)$ and the TEM observation of Weibel-Palade (WP) bodies (23).

Infection of endothelial cells: For transmission electron microscopy (TEM) studies, $25 \mathrm{~cm}^{2}$ tissue culture flasks (Costar) were seeded with HE cells in media and propagated to confluence. For scanning electron microscopy (SEM) and light microscopy studies, 24-well tissue culture clusters (Costar) containing 12-mm diameter glass coverslips were seeded with $\mathrm{HE}$ cells and propagated to confluence. Monolayers were infected at a multiplicity of infection (MOI) of $1.0 \mathrm{MLD} 50 / \mathrm{cell}$. In parallel control studies, uninfected mouse spleen material was pipetted into the flasks and wells containing $\mathrm{HE}$ cells. Suspensions of infected or uninfected spleen material were allowed to adsorb onto the $\mathrm{HE}$ cells for $1 \mathrm{hr}$ followed by two rinses with 
EBSS. Subsequently the $\mathrm{HE}$ cells were incubated at $35 \mathrm{C}$ with culture growth media which were changed on day 8 post infection (PI). Flasks and coverslips were examined by Giemsa or the indirect fluorescent antibody technique (IFA) for the presence of ehrlichiae at $1 \mathrm{hr}$ and on days 4, 8, 10, 12, 14, and 16. Flasks for TEM studies and coverslips for SEM studies were processed on days 10, 12, 14, and 16 PI.

Fluorescence and light microscopy for E. sennetsu: For IFA staining, coverslips or cytospin preparations containing the infected HE cells were used by a modification of the method of Ristic et al (24). Human anti-E. sennetsu (provided by Dr. N. Tachibana) was used as primary antiserum. Fluorescein-labelled goat antihuman IgG, IgA, and IgM (Behringwerke, Marburg, West Germany) were used as the secondary conjugate. Stained preparations were observed and photographed with a Leitz Ortholux UV microscope (E. Leitz, Inc., Rockleigh, NJ, USA).

Scanning electron microscopy: Glass coverslips containing the infected HE cell monolayers were removed from the growth media on days $10,12,14$, and 16 PI and washed three times with $0.1 \mathrm{M}$ phosphate buffer (PB), pH 7.4 prior to 1 hr fixation at $4 \mathrm{C}$ with PB-2.5\% glutaraldehyde (Polaron Instruments, Inc., Doylestown, PA, USA). Fo1lowing fixation, samples for SEM were processed by a modification of the method of Hayat (25) and mounted on specimen stalks with silver paint (Ernest F. Fullam, Inc., Schenectady, NY, USA). The cell surfaces were coated with carbon (Hitachi Hus-5B High Vacuum Evaporator, Naka Works, Mito city, Japan) and gold (Eiko IB-2 Ion Coater, Eiko Engineering, Ibaraki, Japan). The specimens were examined on a Hitachi S450 Scanning Electron Microscope operating at $15-20 \mathrm{kV}$.

Transmission electron microscopy: Specimens for TEM were harvested by scraping by a rubber policeman and centrifuged at $1200 \mathrm{xg}$ for $10 \mathrm{~min}$. The pellets were washed twice with PB and fixed in 2.5\% glutaraldehyde in PB for 1 hr at 4 C. The specimens were dehydrated through a graded series of ethanol, and embedded in Epon 812 (Tousimis Research Corp., Rockville, MD, USA) by the method of Luft (26). U1trathin sections $(600 \AA)$ were cut on a Sorval1 MT-2B ultramicrotome (Dupont Co., Instrument Products Biomedical Division, Newtown, CT, USA) using a diamond knife (Dupont), stained with uranyl acetate and lead citrate, and then examined on a Hitachi H300 Transmission Electron Microscope operating at $50-75 \mathrm{kV}$.

\section{RESULTS}

Cells obtained by collagenase treatment of human umbilical cord veins were confirmed to be of endothelial origin by morphological and immunological means. Phase contrast microscopy revealed monolayers of homogeneous closely opposed cultured cells, polygonal in shape with ovoid central nuclei and poorly defined cell edges. TEM demonstrated the presence of WP bodies (Fig. 5a) and bundles of microfilaments (Fig. 4a) as described by Jaffe et al (21). WP bodies are rod-shaped electron-dense crystalloid structures which appear membrane bound. The endothelial origin of the umbilical cord-derived cells was further demonstrated by the presence of antihemophilic factor or factor VIII by specific indirect immunofluorescence. Both primary HE cells as well as cells passaged up to 10 times consistently demonstrated these characteristic endothelial cell indicators.

Light microscopic examination of Giemsa-stained materials showed less than $1 \%$ infected cells prior to day 10 . Cell infection rates of $4-5 \%$ at 10 days post-E. sennetsu inoculation were observed. By days 14-16, an average of 95-100\% were infected. By day 16, infected cells were rapidly detaching from the flask surface, 
Fig. 1. E. sennetsu in human umbilical vein derived endothelial cells demonstrating various degrees of infection; stained by the indirect fluorescent antibody technique (a). Giemsa stained $E$. sennetsu-infected $\mathrm{HE}$ cell (b). Bars, $5 \mu \mathrm{m}$.

Fig. 2. Scanning electron micrograph of HE cells heavily infected with $E$. sennetsu demonstrating pleomorphism and variable sizes of ehrlichiae. (Inset) Uninfected HE cell. Bars, $5 \mu \mathrm{m}$.

Fig. 3. Transmission electron micrograph of an $\mathrm{HE}$ cell at an advanced stage of infection with eccentric nucleus. Note electron dense (thin arrows) and less dense (thick arrow) forms of the organism. (Inset) An infected HE cell demonstrating a similar organism distributive pattern within the cytoplasm stained by the indirect fluorescent antibody technique. Bars, $1 \mu \mathrm{m}$.

Fig. 4. Transmission electron micrograph of an HE cell infected with $E$. sennetsu (ES). Note constriction (arrowheads) suggesting binary fission; Golgi apparatus (GA); bundle of microfilaments (MF); mitochondrion (M). There is a high degree of pleomorphism and size variation among the ehrlichiae (a). Bar, $0.5 \mu \mathrm{m}$. "Peanut" shaped ehrlichia suggesting an early stage of binary fission (b). Late stage of binary fission (c). Bars, $0.1 \mu \mathrm{m}(\mathrm{b} \& \mathrm{c})$.

Fig. 5. Transmission electron micrograph of an HE cell infected with E. sennetsu; a Weibel Palade body (WP), characteristic of the HE cell, is shown. Note both individual organisms (small arrowhead) and cluster (large arrowhead) of ehrlichiae (a). Cluster of ehrlichiae arranged in a palisade enclosed within a membrane bound vacuole (b). Bars, $0.2 \mu \mathrm{m}$.

Fig. 6. Transmission electron micrograph of an HE cell infected with $E$. sennetsu. The vacuole membrane (arrows) encloses the cell cluster. A distinct cell wall (CW) and plasma membrane (PM) surrounds each organism. Bar, $0.1 \mu \mathrm{m}$.

Fig. 7. Transmission electron micrograph of an HE cell infected with E. sennetsu demonstrating the ehrlichiae wrapping around each other surrounded by a vacuole membrane (a) and (b). Bars, $0.1 \mu \mathrm{m}$.

Fig. 8. Transmission electron micrograph of an HE cell infected with E. sennetsu. Cell is lysing with subsequent release of ehrlichiae (ES). Note high degree of vacuolation and presence of degenerating mitochondria (DM) and nucleus (N). Bar, $1 \mu \mathrm{m}$. 
Fig. 1.
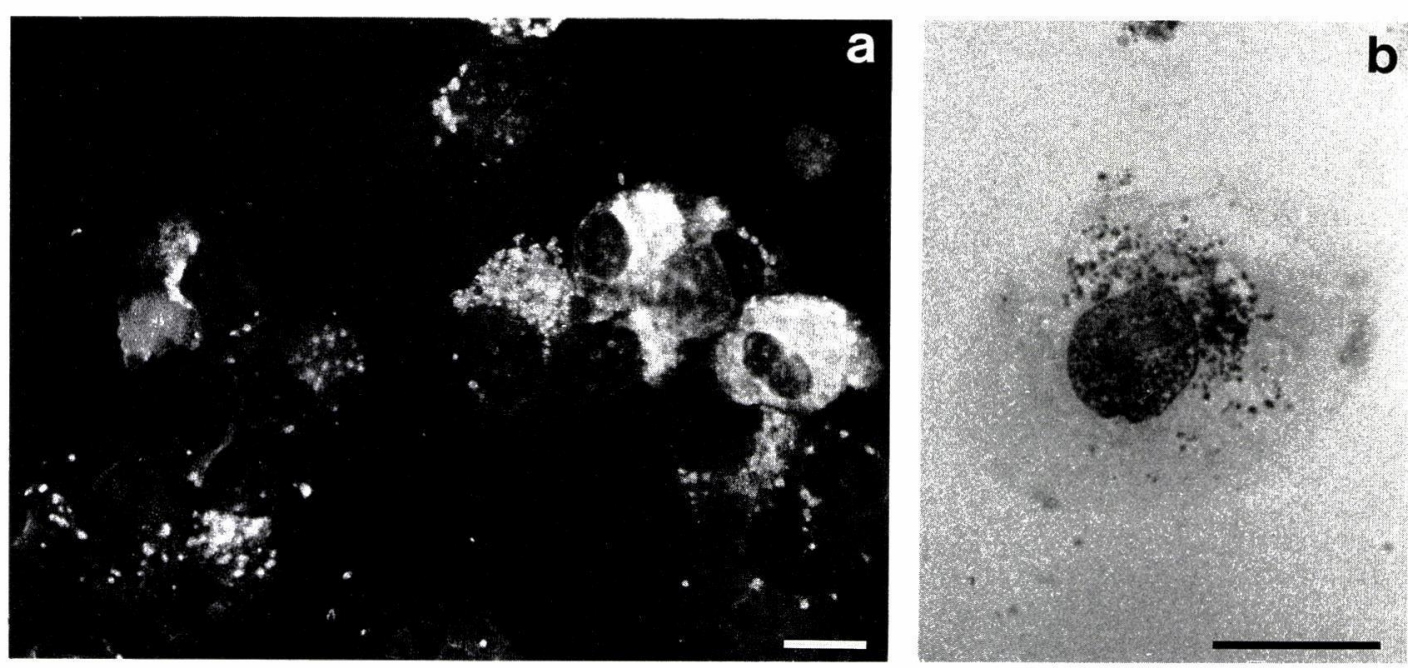

Fig. 2 .

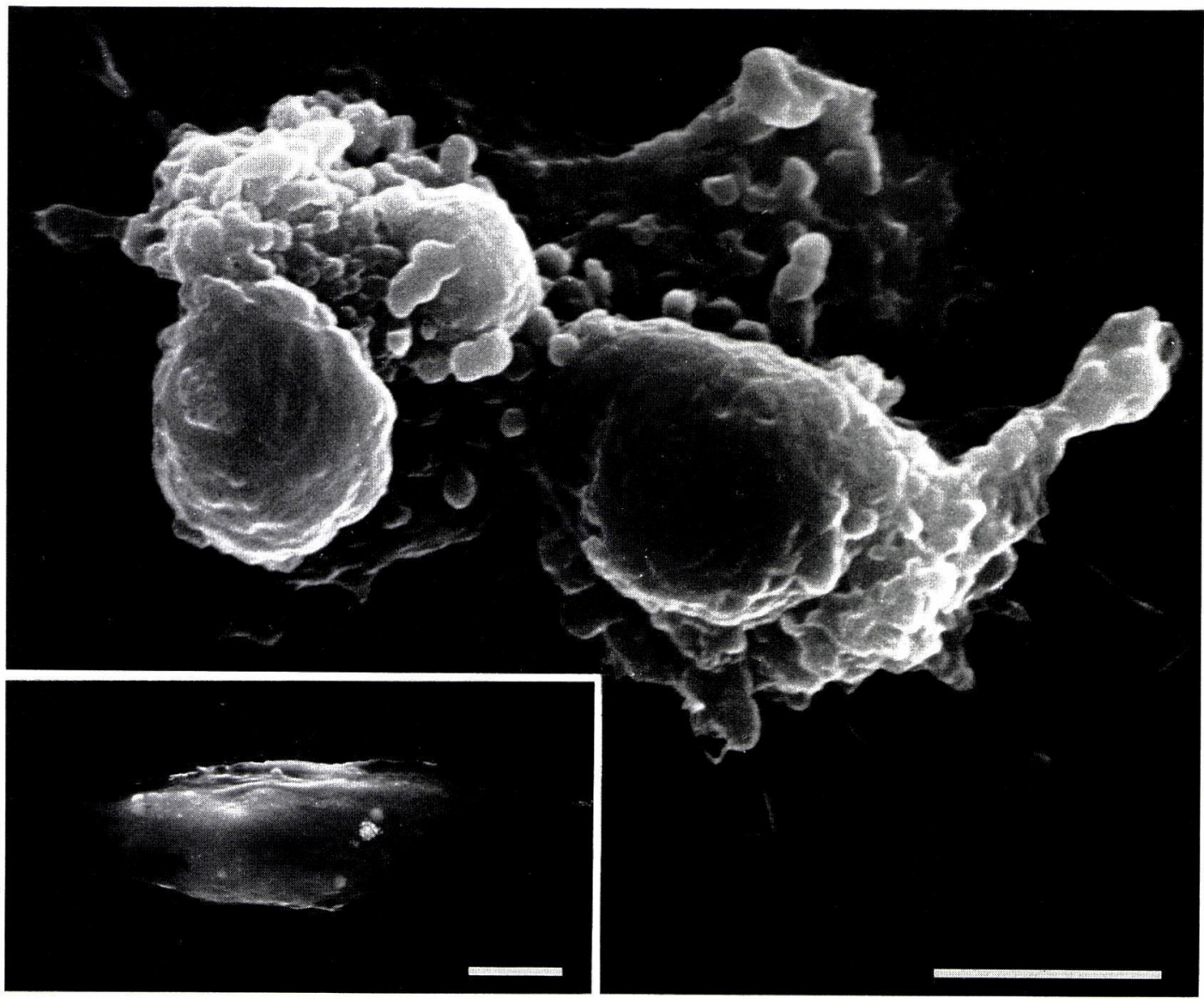


Fig. 3.

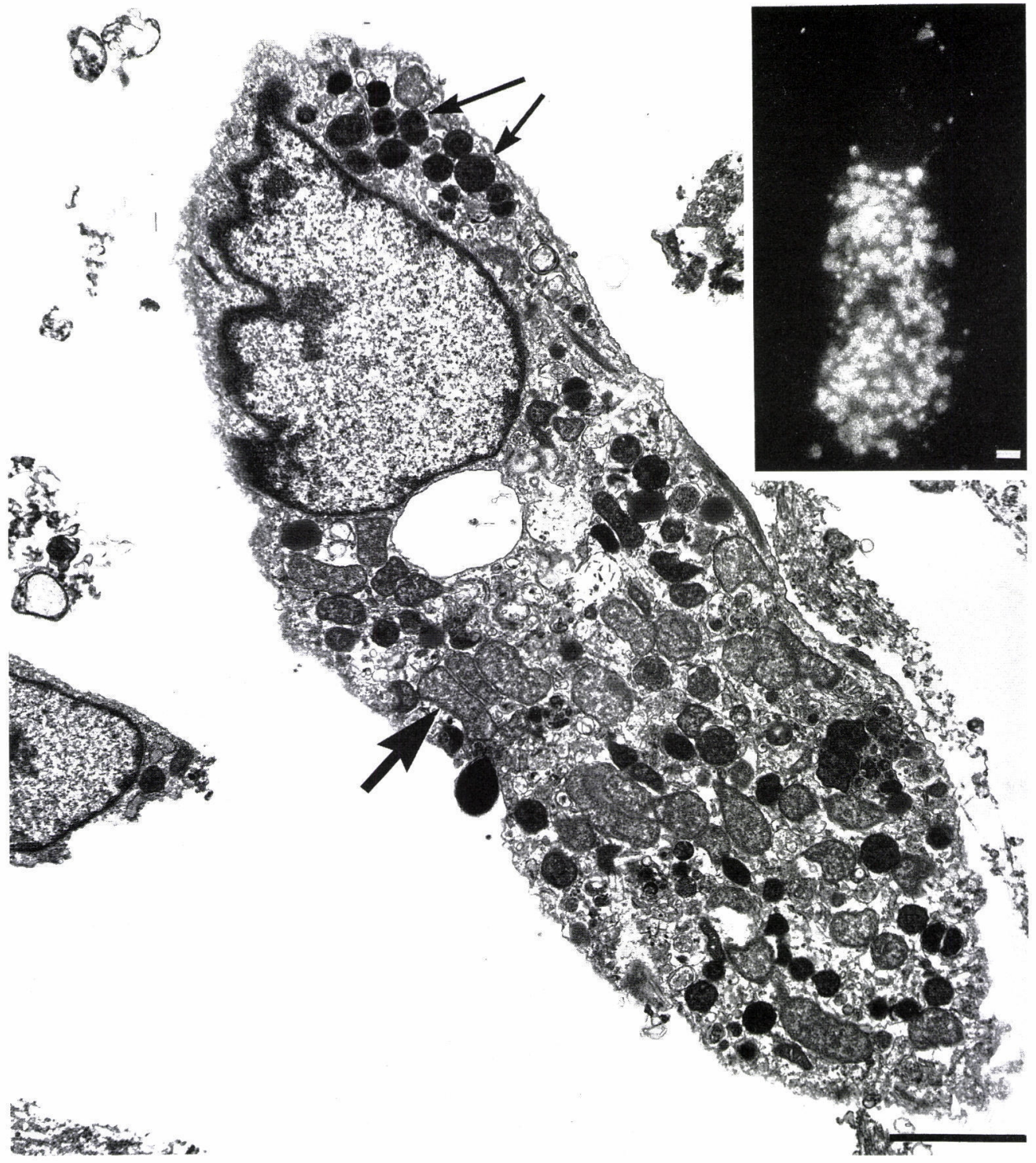


Fig. 4.
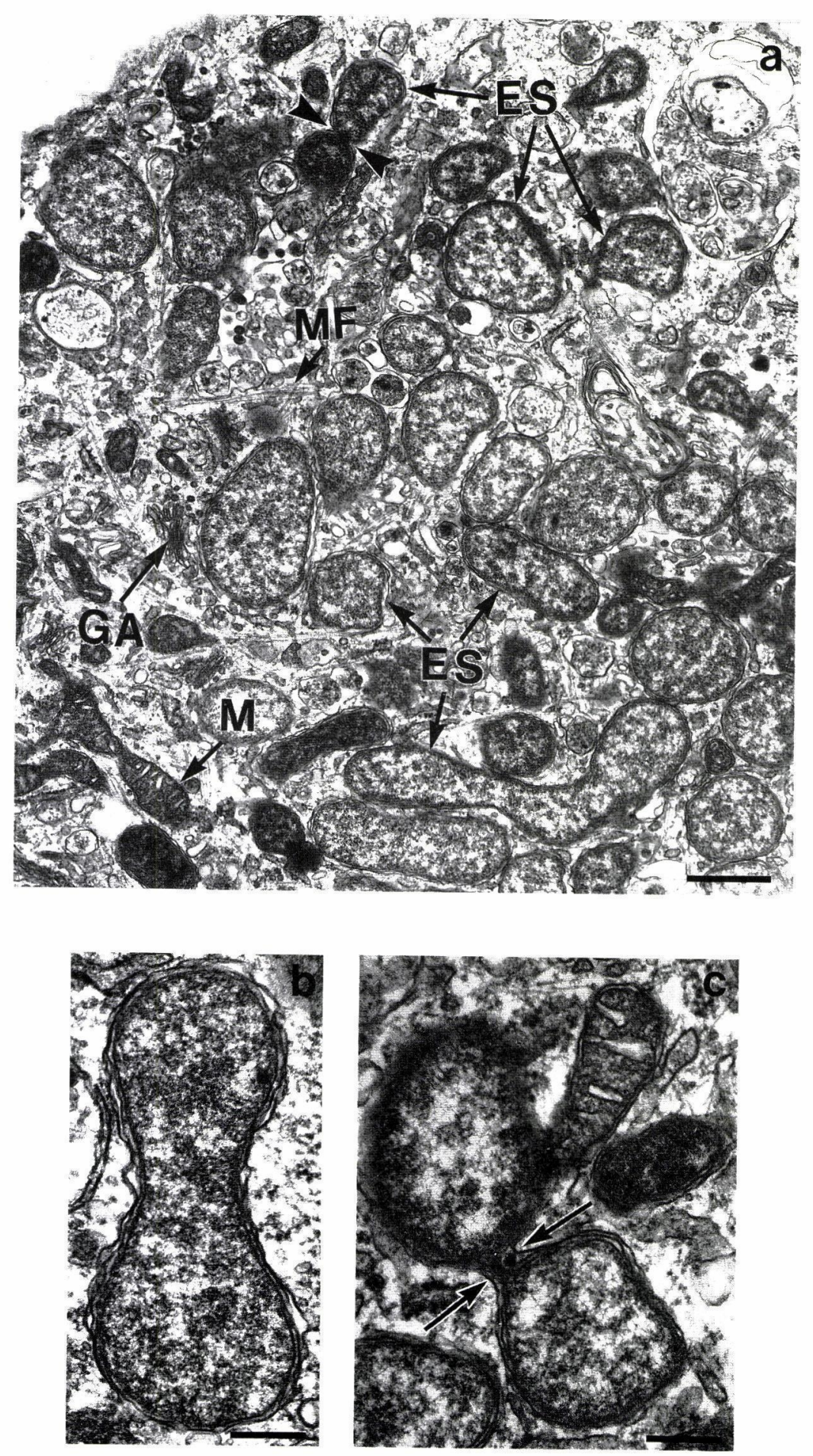
Fig. 5 .
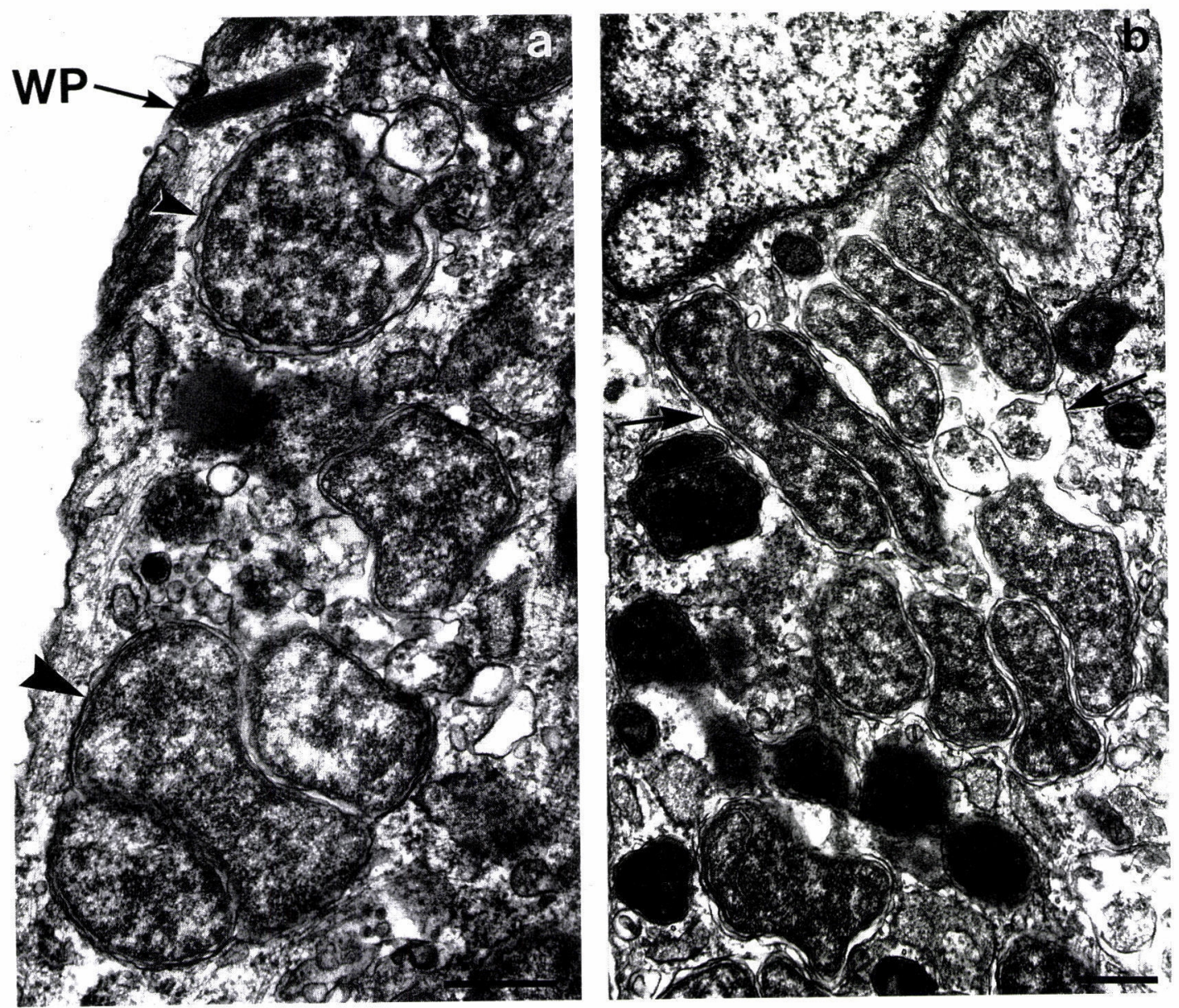
Fig. 6.

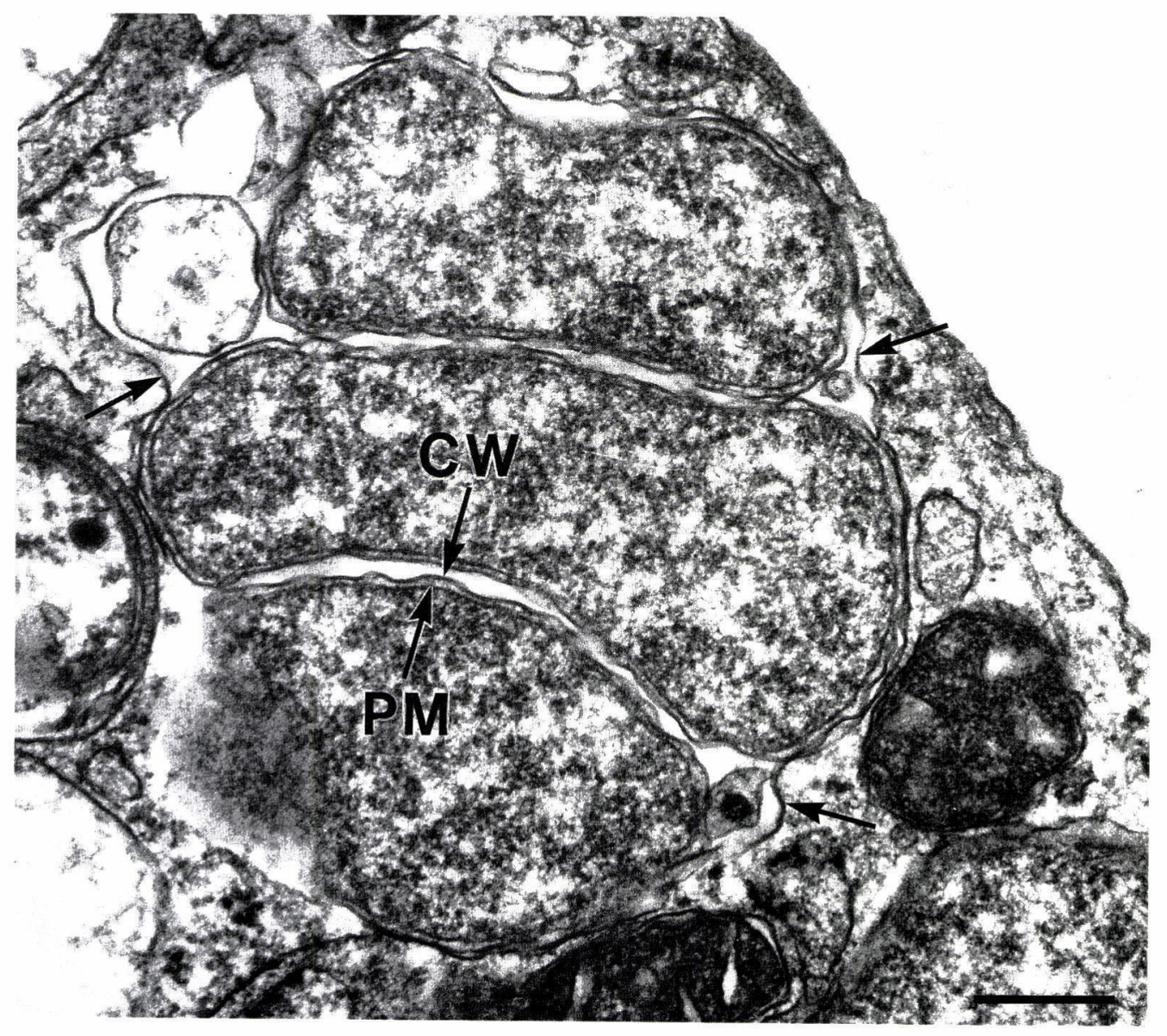


Fig. 7.
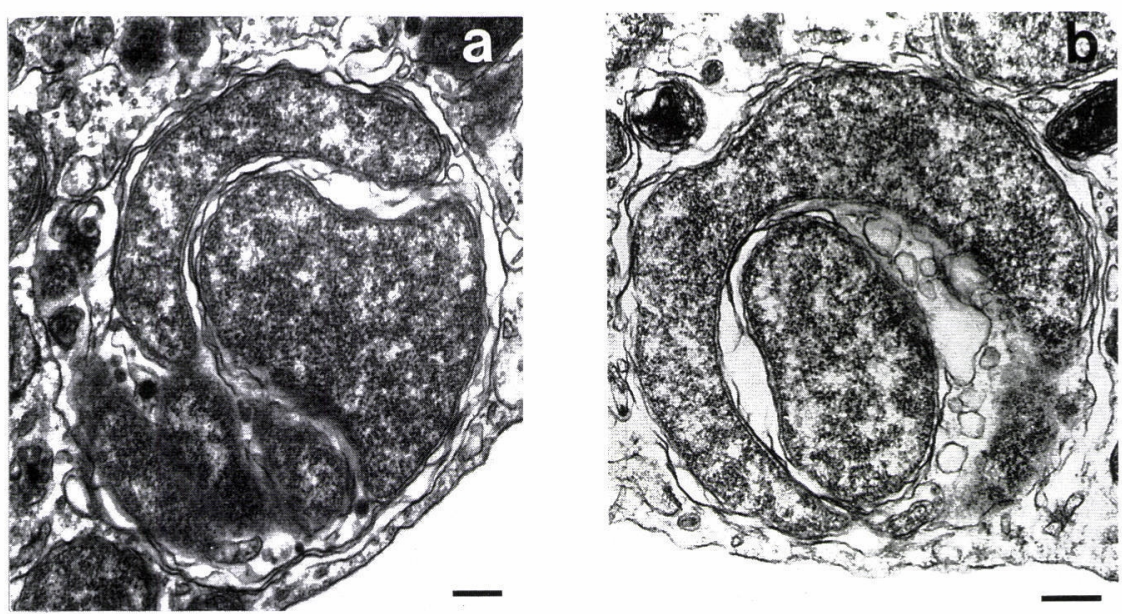

Fig. 8 .

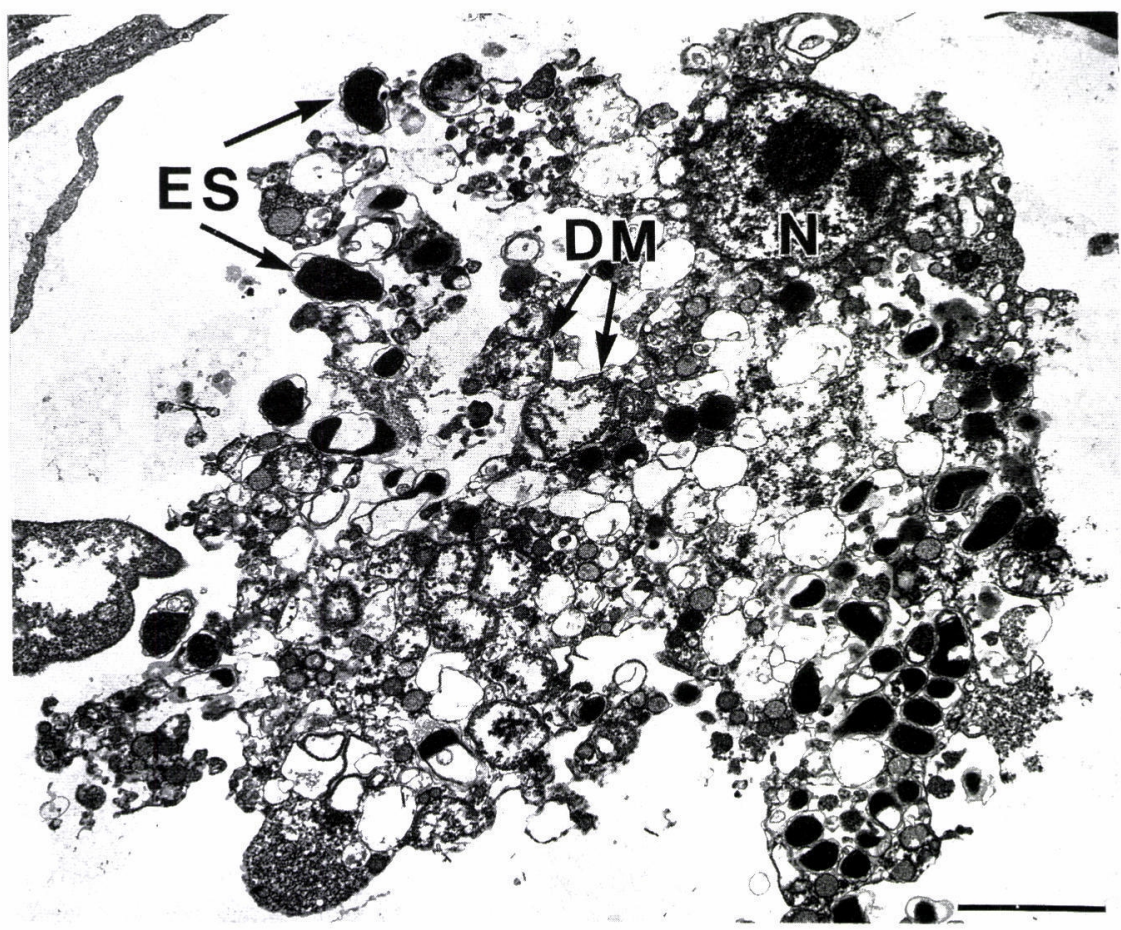


whereas uninfected control cells remained attached. IFA staining of infected HE cells confirmed that organisms seen were $E$. sennetsu. The heavily infected cells frequently revealed a concentration of intracellular organisms in the perinuclear region giving rise to a "crescent" effect about the nucleus (Fig. 1a). Distribution patterns of organisms within the fluorescein-lebelled cells were similar to those seen with Giemsa. The ehrlichiae as seen by both IFA and Giemsa (Fig. 1b) appeared as loosely scattered distinct organisms as well as in clusters.

SEM studies revealed the presence of numerous pleomorphic ehrlichiae extending from the surface of the heavily infected intact HE cells (Fig. 2). "Peanut"-shaped structures were also apparent by SEM. Extracellular chaining of organisms, a characteristic of the release process of $R$. tsutsugamushi through host cell membrane (27), was not evident. The uninfected $\mathrm{HE}$ cell (inset) exhibits no such ehrlichial growth. TEM studies of $E$. sennetsu-infected HE cells revealed patterns similar to those seen in Giemsa and fluorescein-stained preparations (Fig. 3). Ehrlichiae were not seen in any TEM micrographs of $\mathrm{HE}$ cells prior to day $10 \mathrm{PI}$, whereas most cells were heavily infected by day 14. The growth forms within the infected host cells were highly pleomorphic and variable in size, ranging $0.2-0.6 \mu \mathrm{m}$ in diameter and $0.5-3$ $\mu \mathrm{m}$ in length. The ehrlichiae demonstrated a wide range of density from small electron dense to larger less dense forms (Fig. 3). Morphological variations of individual organisms included rod-like, round and irregular forms (Fig. 4a). "Peanut"-shaped forms (Fig. 4b) suggested cells in the early stages of binary fission. Ehrlichiae in later stages of fission were also evident (Fig. 4c).

Membrane-bound vacuoles contained either single organisms (Fig. 5a) or clusters of ehrlichiae (Figs. 5 and 6 ). The vacuolar membrane was clearly seen. Each organism within each vacuole demonstrated both a distinct plasma membrane and a cell wall (Fig. 6). Various arrangements of ehrlichial clusters were present including palisade formations (Fig. 5b), as well as organisms which appeared to be wrapped or twisted around each other (Fig. 7). Both rippled cell walls as well as distended cell walls were frequently observed (Figs. 4a and 5a). Ehrlichiae were found only in the cytosol and not within the nucleus. Even very heavily infected cells failed to show the presence of intranuclear ehrlichiae in the TEM studies.

TEM examination of the HE cells harvested on day 14 PI revealed E. sennetsuinduced changes at the ultrastructural level. Vacuolation with little apparent Golgi activity, as evidenced by the lack of Golgi apparatus, was a prominent feature. Fine granular proteinaceous substances were found within the vacuoles and the cytosol. In contrast, a parallel examination of uninfected $\mathrm{HE}$ cells revealed no such granular material or vacuolation. In this stage of infection there was reduction and dilation of rough endoplasmic reticulum (RER) and slight swelling of the mitochondria. The nuclei remained intact and the nuclear membranes clearly discernible. The very heavily infected cells maintained their integrity prior to day $16 \mathrm{PI}$. We observed 
one example suggesting budding as a mechanism of release of the organisms from the cell. By day 16, mitochondria and nuclei were degenerating; severely damaged highly vacuolated $\mathrm{HE}$ cells were lysing thereby releasing large numbers of intact electrondense E. sennetsu into the culture medium (Fig. 8).

\section{DISCUSSION}

$E$. sennetsu shares several ultrastructural features with organisms of the genera Chlamydia and Rickettsia (6). Nevertheless, we noted several differences between $E$. sennetsu and these other rickettsial organisms. Extreme pleomorphism, uncharacteristic of the genus Rickettsia which tends to be distinctly rod shaped or coccobacillary, is characteristic of the Ehrlichia spp. $(6,28,29)$. We found the variety of sizes and shapes of $E$. sennetsu in $\mathrm{HE}$ cells to be far greater than that reported for $E$. equi (28) or $E$. canis (11). The variation of growth forms in the $E$. sennetsuinfected HE cells included small electron-dense bodies and larger, less dense bodies. This variety of forms suggested to us the possibility of a developmental cycle as described for the chlamydia $(20,30)$ which includes elementary bodies, intermediate bodies and reticulate bodies. Although we were unable to detect a form comparable to intermediate bodies, structures similar to the low electron density reticulate bodies and electron-dense elementary bodies of chlamydia were frequently observed. These variations in growth forms have not been reported in TEM examinations of $E$. sennetsu-infected non-HE cell cultures $(4,6,7)$. It is possible that the nature of the HE cell environment may be responsible for or conducive to formation of a variety of forms which are possibly representative of the true infection cycle as it occurs in naturally infected HE cells.

One feature of $E$. sennetsu pathogenesis which should be addressed is the mechanism of release from the host cell. Whereas the means of cell release of $R$. tsutsugamushi from HE cells appears to be both by cell lysis and budding through the plasma membrane (27), our in vitro findings indicated cell lysis to be the primary mechanism of release from the host cell as is the means of release for $R$. rickettsii from infected HE cells (31). There was no evidence of budding or extrusion of $E$. sennetsu through the HE cell plasma membrane as a mode of release from the host cell.

Intracellular $E$. sennetsu was first detected by TEM on day 12 PI. Silverman's TEM examination of $R$. pickettsii (31) in HE cells, in contrast showed vastly increased numbers of organisms by day 8 PI. The dramatic RER dilation demonstrated by Silverman (31) in $R$. rickettsii-infected $\mathrm{HE}$ cells was not observed in our $E$. sennetsu-HE cell model. However, in both models, varying degrees of damage to the mitochondria were observed prior to cell degeneration and lysis at which time cristae were totally destroyed.

These findings suggest common or similar mechanisms of pathogenicity of $E$. sennetsu 
as occurs for other rickettsiae, although the degree of similarity may vary considerably. Differences in the time required to induce evident host-cel1 changes is dependent upon the pathogenecity and the quantity of organims with which the infection is initiated as well as the growth rate of the pathogens within the host cell. If the slow in vitro growth rate of $E$. sennetsu is a true reflection of in vivo events, it can be extrapolated that the human host immune response may be more readily able to cope with an $E$. sennetsu infection, modifying the course of disease, than with a quantitatively similar $R$. mickettsii infection. Comparative growth studies of other ehrlichial species, Chlamydia and $E$. sennetsu should also help to elucidate the mechanism of pathogenicity of $E$. sennetsu and further allow the application of this in vitro $\mathrm{HE}-\mathrm{cell}$ model to the study of sennetsu fever.

\section{ACKNOWLEDGEMENTS}

We thank Dr. Lim Teong Wah, Director, IMR, for his support of this study; Teh Hamidah, IMR Electron Microscopy Laboratory for technical assistance in scanning electron microscopy studies;W.K. Wong, IMR, for photographic assistance; and Lee Eng Kee for his assistance in isolating and culturing HE cells.

\section{REFERENCES}

1. Misao, T. and Kobayashi, Y. (1955): Kyushu J. Med. Sci., 6, 145-152.

2. Ristic, M. and Huxso11, D. L. (1984): In N. R. Krieg and J. G. Holt [eds.], Bergey's Manual of Systematic Bacteriology. p.704-711. Williams \& Wilkins,
Baltimore, MD. 3. Holland, C. J., Ristic, M., Husxo11, D. L., Cole, A. I. and Rapmund, G. (1985):
Infect. Immun., 48, 366-372. 4. Hoilien, C. A., Ristic, M., Huxso11, D. and Rapmund, G. (1982): Infect. Immun.,

5. Sugi, Y. (1960): Fukuoka Acta Med., 51, 1056-1060.

6. Anderson, D. R., Hopps, H. E., Barile, M. F. and Berheim, B. G. (1965): J. Bacterio1., 90, 1387-1404.

7. Shirahama, S. (1967): J. Jap. Assoc. Infect. Dis., 41, 82-98.

8. Minamishima, Y. (1965): Japan. J. Microbio1., 9, 75-86.

9. Allen, A. C. and Spitz, S. (1945): Amer. J. Pathol., 21, 603-682.
10. Brezina, R., Murray, E. S., Tarizzo, M. L. and Bogel, K. (1973): Bull. WHO,
49, 433-442.

11. Simpson, C. F. (1974): Infect. Immun., 10, 590-596.

12. Silverman, D. J. and Bond, S. B. (1984): J. Infect. Dis., 149, 201-206.

14. Hanaoka, M. (1961): Ann. Rep. Inst. Virus Res. Kyoto Univ., 4, 83-117.

15. Tachibana, N., Kusune, E., Yokota, T., Fukuma, M., Hisano, S. and Tsuda, K. (1979): Kansenshogaku Zasshi, 53, 417-422.

16. Bovarnik, M. R., Miller, J. C. and Snyder, J. C. (1950): J. Bacteriol., 59,

17. Shirai, A., Huxso11, D. L., Dohany, A. L., Montrey, R. D., Werner, R. M. and Gan, E. (1982): Amer. J. Trop. Med. Hyg., 31, 395-402.

18. Jackson, E. B. and Smade1, J. E. (1951): Amer. J. Hyg., 53, 326-331.

19. Finney, D. J. (1964): In Statistical Method in Biological Assay. 524p.

20. Gimbrone, M. A., Jr. (1976): In T. Spaet [ed.], Progress in Homeostasis and Thrombosis. p.1-2. Grune and Stratton, New York. 
21. Jaffe, E. A., Nachman, R. L., Becker, C. G. and Minick, C. R. (1973): J. Clin. Invest., 52, 2745-2756.

22. Jaffe, E. A. (1977): New Eng1. J. Med., 296, 377-383.

23. Jaffe, E. A., Hoyer, L. W. and Nachman, R. L. (1973): J. Clin. Invest., 52, 2757-2764.

24. Ristic, M., Huxso11, D. L., Weisiger, R. M., Hildebrandt, P. K. and Nyindo, M. B. A. (1972): Infect. Immun., 6, 226-231.

25. Hayat, M. A. (1981): Fixation for scanning electron microscopy. Academic Press, New York.

26. Luft, J. H. (1961): J. Biophys. Biochem. Cyto1., 9, 409-414.

27. Ewing, E. P., Jr., Takeuchi, A., Shirai, A. and Osterman, J. V. (1978): Infect. Immun., 19, 1068-1075.

28. Sells, D. M, Hildebrandt, P. K., Lewis, G. E., Jr., Nyindo, M. B. A. and Ristic, M. (1976): Infect. Immun., 13, 273-280.

29. Hildebrandt, P. K., Conroy, J. D., McKee, A. E., Nyindo, M. B. A. and Huxso11, D. L. (1973): Infect. Immun., 7, 265-271.

30. Moulder, J. W. (1984): In N. R. Krieg and J. G. Ho1t [eds.], Bergey's Manual of Systematic Bacteriology. p.729-739. Williams \& Wilkins, Baltimore, MD.

31. Silverman, D. J. (1984): Infect. Immun., 44, 545-553. 